\title{
Pelatihan Pengenalan Game Maker Studio dan Workshop Pembuatan Game di SMAK Terang Bangsa Cirebon
}

\author{
Harya Bima D. ${ }^{1)}$, Yulius Denny P. ${ }^{2)}$, Yulia Ery K. ${ }^{3)}$, Paramaresthi W.4) Henri S.) Tedi L.M() \\ Informatika, Fakultas Industri Kreatif Institut Teknologi dan Bisnis Kalbis \\ Jalan Pulomas Selatan Kavling 22, Jakarta 13210 \\ Email: harya.dirgantara@kalbis.ac.id
}

\begin{abstract}
Games are one of the most popular applications used at this time. Games can also be a means of learning and a means to train cognitive abilities. One genre of games that can train cognitive abilities is action. In this training, the participants were given the basic theory of game development as well as an introduction to one of the game engines, namely Game Maker Studio. The training activities that were carried out on April 8, 2020, it can be concluded that this training activity provides knowledge about the concept of games and applications used to make games. The participants seemed very enthusiastic in following the training material. The curiosity of the participants was very high, this made the training material conveyed well. This training material can be developed according to the creativity of the students in making interesting games.
\end{abstract}

Keywords: cognitive abilities, creativity, game, game maker studio

Abstrak: Game merupakan salah satu aplikasi yang populer digunakan pada masa ini. Game juga dapat menjadi sarana pembelajaran dan sarana untuk melatih kemampuan kognitif. Salah satu genre game yang dapat melatih kemampuan kognitif adalah action. Pada pelatihan ini, para peserta diberikan teori dasar pembuatan game serta pengenalan salah satu game engine, yaitu Game Maker Studio. Kegiatan pelatihan yang telah dilaksanakan pada tanggal 8 April 2020 dapat disimpulkan bahwa kegiatan pelatihan ini memberikan pengetahuan mengenai konsep permainan dan aplikasi yang digunakan untuk membuat permainan. Para peserta terlihat sangat antusias mengikutinya materi pelatihan. Keingintahuan peserta sangat besar, hal ini menjadikan materi pelatihan dapat tersampaikan dengan baik. Materi pelatihan ini dapat dikembangkan sesuai dengan kreativitas para siswa-siswi dalam membuat permainan yang menarik.

Kata kunci: game, game maker studio, kemampuan kognitif, kreativitas

\section{PENDAHULUAN}

Di era informasi dimana Teknologi Informasi dan Komunikasi sudah menjadi bagian dari kehidupan sosial dan budaya masyarakat maka tidak heran jika sejak usia muda banyak anak yang sudah mengenal dan menggunakan aplikasi berbasis Teknologi Informasi dan Komunikasi.

Bermain game menggunakan komputer atau pun handphone saat ini adalah salah satu kegiatan yang digemari oleh banyak orang, terutama anakanak dan remaja, mulai dari masa pra sekolah sampai dengan mereka yang sudah kuliah, bahkan banyak orang dewasa yang hobi bermain game (GamingScan, 2020). Bermain game, terutama genre action-shooter dapat meningkatkan kemampuan kognitif, antara lain kemampuan sensitivias visual, kecepatan pemrosesan perseptual, dan pengambilan keputusan perseptual (Bisoglio et al., 2014)(Granic et al., 2014). Game juga dapat difungsikan sebagai media pembelajaran dan kuis evaluasi (Dirgantara et al., 2019)

Berdasarkan hal tersebut di atas kami memilih mengenalkan Game Maker sebagai sebuah aplikasi pembuat game kepada anak-anak di SMA pada kegiatan PKM ini, dengan tujuan agar mereka mengetahui dan tertarik untuk membuat game berbasis TIK, jadi mereka tidak lagi hanya sekedar menjadi pengguna ataupun pemain game melainkan menjadi pembuat game.

Rencana pelatihan akan dilaksanakan selama 3 (tiga) hari di Sekolah Menengah Atas Kristen (SMAK) Terang Bangsa berlokasi di J1. Dr. Setiabudi No. 10, Kesambi, Kecamatan Kesambi, Kota Cirebon, Jawa Barat pada tanggal $6-8$ April 2020. 


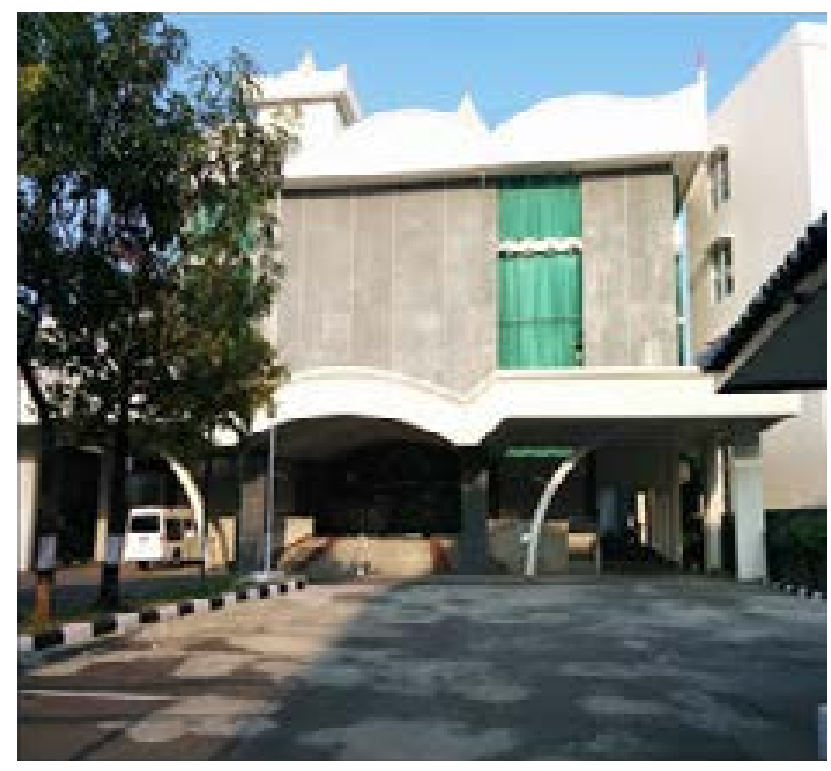

Gambar 1. Kondisi mitra

Identitas mitra, yaitu Sekolah Menengah Atas Kristen Terang Bangsa ditampilkan pada Tabel 1. Jumlah siswa ditampilkan pada Tabel 2, serta Sarana dan Prasarana ditampilkan pada Tabel 3 berikut (Direktorat Jenderal Pendidikan Anak Usia Dini dan Kebudayaan, 2020).

Tabel 1. Identitas Sekolah

\begin{tabular}{cll}
\hline No & \multicolumn{1}{c}{ Data } & \multicolumn{1}{c}{ Keterangan } \\
\hline 1 & Nama Sekolah & SMAK Terang Bangsa \\
\hline 2 & Nama Kepala Sekolah & Paulus Gunawan, S.T \\
\hline 3 & Alamat Sekolah & Jl. Dr. Setiabudi No. 10 \\
\hline 4 & $\begin{array}{l}\text { NPSN (Nomor Pokok } \\
\text { Sekolah Nasional) }\end{array}$ & 60726457 \\
\hline 5 & Kecamatan & Kesambi \\
\hline 6 & Kabupatern & Cirebon \\
\hline 7 & Propinsi & Jawa Barat \\
\hline 8 & Kode Pos & 45134 \\
\hline 9 & Telepon & $(0231)$ 8332941 \\
\hline 10 & Email & \\
\hline 11 & Status & Swasta \\
\hline 12 & Akreditasi & A \\
\hline
\end{tabular}

Tabel 2. Jumlah Siswa

\begin{tabular}{ccc}
\hline & Kelas & Jumlah \\
\hline Kelas 10 & 46 \\
\hline Kelas 11 & 41 \\
\hline Kelas 12 & Total Jumlah Guru & 35 \\
\hline & $\mathbf{1 2 2}$ \\
\hline
\end{tabular}

Tabel 3. Sarana dan Prasarana

\begin{tabular}{|c|c|c|}
\hline Ruang & Jumlah & Keadaan \\
\hline Ruang Kelas & 7 & Baik \\
\hline $\begin{array}{l}\text { Laboratorium } \\
\text { Komputer }\end{array}$ & 1 & Baik \\
\hline Laboratorium IPA & 1 & Baik \\
\hline Perpustakaan & 1 & Baik \\
\hline Sanitasi & 4 & Baik \\
\hline
\end{tabular}

\section{METODE PELAKSANAAN}

\section{A. Persoalan Mitra}

Persoalan yang dihadapi mitra saat ini adalah bagaimana meningkatkan kompetensi siswa dalam bidang penggunaan software aplikasi, khususnya agar para siswa memiliki kompetensi tambahan berupa kemampuan menggunakan software aplikasi untuk membuat game komputer. Berdasarkan persoalan tersebut maka para Dosen Informatika menyimpulkan perlunya memberikan materi pelatihan dan workshop game.

\section{B. Status Sosial Mitra, Lokasi Mitra, dan Sarana Komunikasi Mitra}

Mitra PKM adalah SMA Kristen Terang Bangsa sebuah Lembaga Pendidikan Jenjang SMA yang dimiliki oleh Yayasan Swasta, Status Akreditasi A, SK Pendirian Sekolah 1632.HT.01.02 TH. 2007, SK Izin Operasional: 421/0792/DISDIK/2015. Sekolah didirikan di atas tanah seluas $2978 \mathrm{~m} 2$ di kota Cirebon.

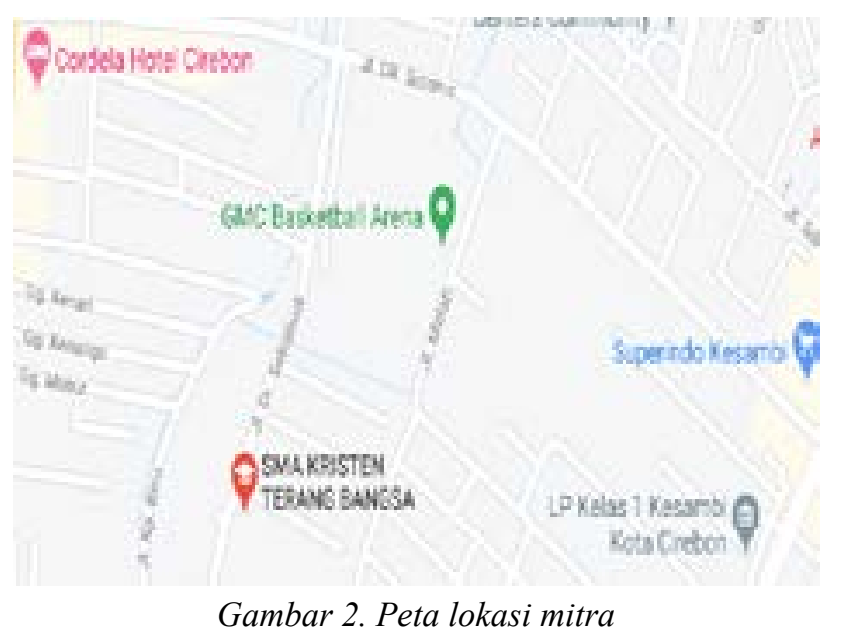

Sekolah Menengah Atas Kristen (SMAK) Terang Bangsa berlokasi di Jl. Dr. Setiabudi No. 10, Kesambi, Kecamatan Kesambi, Kota Cirebon, Jawa Barat. Berdiri sejak tahun 2012, saat ini status Akreditasi "A".

SMAK Terang Bangsa menempati gedung milik sendiri dengan luas tanah 2978 meter persegi, memiliki fasilitas internet fiber optik dengan provider Biznet, yang dilengkapi ruang-ruang kelas yang nyaman. Tersedia juga kapel, laboratorium komputer, ruang serba guna, Ruang UKS, Usaha kesehatan Gigi Sekolah ( UKGS ). Perpustakaan, lapangan olahraga, toko sekolah dan kantin.

Sarana komunikasi yang dimiliki oleh Mitra adalah telepon, handphone, WA dan Email. Tim PKM Prodi Informatika menjalin komunikasi dengan mitra melalui semua sarana komunikasi yang dimiliki oleh mitra, namun disesuaikan dengan kebutuhan.

\section{Perencanaan Kegiatan Pengabdian Kepada Masyarakat}

Kegiatan Pengabdian Kepada Masyarakat dilaksanakan pada Laboratorium Komputer dengan peserta adalah siswa-siswi SMA Kristen Terang 
Bangsa. Adapun materi Pelatihan adalah pengenalan Game Maker Studio dan membuat game shooter sederhana. Rencana ini didiskusikan dalam rapat Tim Dosen Program Studi Informatika Fakultas Industri Kreatif Institut Teknologi dan Bisnis Kalbis (Kalbis Institute) yang tergabung ke dalam Tim Pengabdian Kepada Masyarakat (PKM) pada 13 Januari 2020 jam 08.00 - 17.00 WIB di ruang rapat dosen Lantai 2 Kampus Institut Teknologi dan Bisnis Kalbis Jalan Pulomas Selatan Kav.22 Jakarta Timur.

Diskusi ini untuk membicarakan PKM yang merupakan salah satu wujud Tri Dharma Perguruan Tinggi. Hasilnya adalah kesepakatan untuk melakukan PKM dengan mitra SMA Kristen Terang Bangsa. Kegiatan observasi tim PKM ke SMA Kristen Terang Bangsa dilakukan pada tanggal 16 Januari 2020 oleh Tim Dosen Program Studi Informatika Industri Kreatif Institut Teknologi dan Bisnis Kalbis (Kalbis Institute) yang tergabung dalam Tim Pengabdian Kepada Masyarakat.

Tim PKM disambut oleh Bapak Paulus Gunawan, S.T. Pada pertemuan ini dilakukan pembicaraan awal dan perkenalan antara tim PKM Kalbis dengan mitra SMA Kristen Terang Bangsa. Tujuan diadakannya observasi awal adalah untuk menggali kembali persoalan serta kebutuhan para guru SMA Kristen Terang Bangsa dalam memahami permasalahan mitra.

\section{Penawaran Kerja Sama dan Kesediaan Kerja Sama}

Pada observasi lanjut tanggal 27 Januari 2020 di SMA Kristen Terang Bangsa dibicarakan program dan tema PKM yang diberikan bagi para siswa-siswi SMA Kristen Terang Bangsa. Hasilnya adalah kesepakatan untuk mengadakan PKM dengan judul "Workshop Pengenalan Game Maker untuk Pembuatan Game Plane vs Alien" bagi siswa-siswi SMA Kristen Terang Bangsa pada tanggal 08 April 2020 yang bertempat di Laboratorium Komputer SMA Kristen Terang Bangsa.

Penawaran kerjasama tim PKM kepada mitra disambut dengan baik oleh kepala sekolah dan para siswa SMA Kristen Terang Bangsa. Mereka sangat mendukung untuk dilaksanakannya kegiatan PKM dalam bentuk pelatihan untuk para siswa-siswi SMA Kristen Terang Bangsa. Kesediaan bekerja sama disampaikan pada saat observasi lanjut yang dilaksanakan pada tanggal 27 Januari 2020.

Koordinasi tentang kepastian pelaksanaan dan ketersediaan waktu SMAKristen Terang Bangsa untuk pelaksanaan pelatihan ini dilakukan lewat telepon sambil menginggatkan kembali akan pelatihan yang akan dilaksanakan tanggal 08 April 2020 pada pukul 8.00-17.00 WIB.

\section{E. Pelaksanaan Kegiatan Pengabdian Kepada Masyarakat}

Kegiatan pelatihan dilaksanakan pada hari Senin tanggal 08 April 2020 pada pukul 8.00-17.00 WIB di Laboratorium Komputer SMA Kristen Terang Bangsa. Pelatihan diberikan oleh Tim PKM dari Prodi Informatika yang berjumlah sebanyak 3 orang. Peserta pelatihan adalah siswa-siswi SMA Kristen Terang Bangsa yang berjumlah 125 orang.

Pukul 08.00 - 08.30 WIB, acara dibuka oleh Bapak Yulius Denny Prabowo, S.T., M.T.I., selaku Ketua Program Studi Informatika Kalbis Institute. Pukul 08.30 - 12.00 WIB acara dilanjutkan dengan sesi materi teori dasar pembangunan game oleh Bapak Tedi Lesmana Marselino, S. Kom., M. Kom. Yang dilanjutkan dengan workshop permainan shooter sederhana dengan narasumber Bapak Harya Bima Dirgantara, S. Kom., M.T.I dan dibantu bapak Yulius Denny Prabowo, S.T., M.T.I. Lalu pada pukul 13.00 - 17.00 WIB, siswa-siswa praktek pembuatan sprite, objek dan event. Materi pelatihan disampaikan oleh Bapak Henri Septanto, S.Kom., M.Kom. dengan didampingi oleh Ibu Yulia Ery Kurniawati, S. Kom., M. Eng. dan Ibu Paramaresthi Windriyani, S. Kom., M. Eng.

\section{HASIL DAN PEMBAHASAN}

\section{A. Evaluasi Pelaksanaan Pengabdian Kepada Masyarakat}

Berdasarkan pelaksanaan kegiatan PKM pada tanggal 08 April 2020 oleh dosen Prodi Informatika Kalbis Institute kepada peserta yaitu siswa-siswi SMA Kristen Terang Bangsa Cirebon sangat antusias dalam mengikuti kegiatan PKM dalam bentuk pelatihan.

Evaluasi kegiatan PKM selama satu hari berjalan dengan lancar mulai dari pembukaan hingga penutupan pelatihan. Pembuatan permainan menggunakan aplikasi Game Maker Studio 1.4 sangat bermanfaat sekali bagi para siswa-siswi SMA Kristen Terang Bangsa Cirebon sebagai salah satu sarana peningkatan komptensi siswa-siswi pada era revolusi industri 4.0.

Adapun kendala yang dihadapi pada saat pelatihan berlangsung adalah tidak semua siswa dapat langsung memahami penjelasan sehingga harus di tuntun dengan mendatangi siswa dan menunjukan secara langsung di monitor computer. 
Akan tetapi semua bisa diatasi dengan cara meminta rekan-rekannya untuk membantu sehingga kegiatan pelatihan tetap berjalan dengan baik.

\section{B. Indikator Keberhasilan}

Indikator keberhasilan kegiatan PKM yaitu dapat dilaksanakannya kegiatan selama satu hari dengan baik dan lancar. Peserta mengikuti kegiatan dan berpartisipasi aktif dalam kegiatan pelatihan, para siswa dan siswi sangat antusias dalam proses persiapan hingga berlangsungnya kegiatan ini. Data yang didapatkan dari kuisoner yang telah diisi oleh peserta yang mengikuti pelatihan memiliki kepuasan dengan nilai Baik. Standar hasil rata-rata dapat dilihat pada tabel 4 dan Rekapitulasi data kuisoner dapat dilihat pada Tabel 5 .

Tabel 4. Standar Hasil Kuesioner

\begin{tabular}{ll}
\hline Interval Kepuasan & Kinerja Layanan \\
\hline $1.00-2.00$ & Kurang \\
\hline $2.01-4.00$ & Cukup \\
\hline $4.01-6.00$ & Baik \\
\hline $6.01-7.00$ & Baik Sekali \\
\hline
\end{tabular}

Tabel 5. Rekapitulasi Hasil Kuesioner

\begin{tabular}{cccccc}
\hline & 1 & 2 & 3 & 4 & 5 \\
\hline 1 & 2 & 9 & 31 & 46 & 27 \\
\hline 2 & 2 & 8 & 20 & 47 & 28 \\
\hline 3 & 6 & 3 & 26 & 46 & 34 \\
\hline 4 & 4 & 5 & 32 & 41 & 33 \\
\hline 5 & 5 & 7 & 25 & 46 & 32 \\
\hline 6 & 3 & 7 & 24 & 34 & 47 \\
\hline 7 & 5 & 10 & 30 & 35 & 35 \\
\hline 8 & 5 & 2 & 31 & 36 & 41 \\
\hline 9 & 1 & 2 & 27 & 38 & 47 \\
\hline 10 & 5 & 4 & 41 & 40 & 25 \\
\hline
\end{tabular}

\section{B. Partisipasi Mitra Dalam Pelaksanaan Pengabdian Kepada Masyarakat}

Partisipasi mitra yaitu kepala sekolah dan siswa/i SMA Kristen Terang Bangsa dalam upaya memahami dan menyadari tentang pentingnya mengikuti pelatihan yang diberikan oleh tim PKM Prodi Informatika Institut Teknologi dan Bisnis Kalbis adalah dengan melakukan:

Diskusi pihak sekolah yang terdiri dari kepala sekolah dan Guru Komputer SMAK Terang Bangsa Cirebon dengan Tim PKM yang merupakan dosen-dosen Prodi Informatika Fakultas Industri Kreatif Institut Teknologi dan Bisnis Kalbis untuk membicarakan kegiatan PKM.

Sekitar 125 orang siswa/i bersedia untuk menghadiri pelatihan yang diberikan oleh Tim PKM
Prodi Informatika pada tanggal 08 April 2020 yang bertempat di SMAK Terang Bangsa Cirebon, Jalan Setiabudi 10 Kesambi Baru Cirebon 45134.

\section{Manfaat Kegiatan Pengabdian Kepada Masyarakat}

Kegiatan PKM ini memiliki 2 manfaat yaitu manfaat bagi Program Studi Informatika dan bagi mitra yaitu SMAK Terang Bangsa Cirebon.

1. Prodi Informatika

Bagi Prodi Informatika, kegiatan PKM ini memberikan manfaat di antaranya: Pemenuhan kewajiban salah satu Tridarma dosen, yaitu pengabdian kepada masyarakat (PKM) bagi dosen Program Studi Informatika; Meningkatkan keahlian dosen melalui proses sharing keahlian bagi mitra; Memperbanyak relasi dengan mitra untuk berbagai fungsi-fungsi positif; dan Memberikan pengalaman baru bagi dosen-dosen Prodi Informatika mengenai pemanfaatan teknologi untuk meningkatkan kompetensi guru dalam menghadapi era industri 4.0. 2. Mitra.

Bagi mitra, SMAK Terang Bangsa Cirebon, PKM ini memberikan manfaat di antaranya: Meningkatkan kreatifitas dan keahlian secara praktikal dalam membuat permainan menggunakan Game Maker Studio; Memberikan pengenalan mengenai konsep permainan dan perangkat pendukung Game Maker Studio dalam pembuatan permainan; dan Memberikan pemahaman-pemahaman baru mengenai dunia kampus Institut Teknologi dan Bisnis Kalbis.

\section{Dokumentasi Kegiatan Pengabdian Kepada Masyarakat}

Dokumentasi kegiatan pengabdian kepada masyarakat di SMAK Terang Bangsa Cirebon seperti pada Gambar 3 sampai dengan Gambar 6.

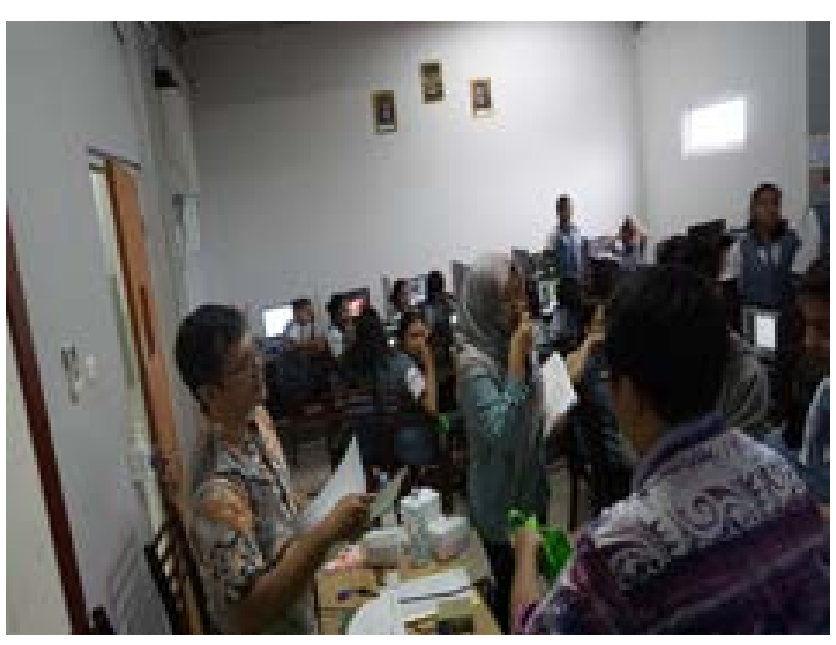

Gambar 3. TIM PKM bersiap untuk pembukaan acara 


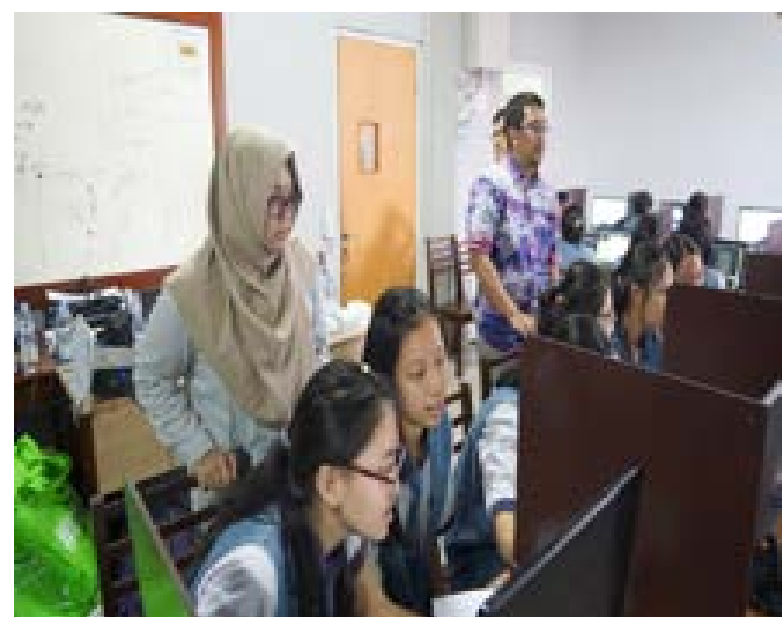

Gambar 4. Para peserta antusias mengikuti pelatihan

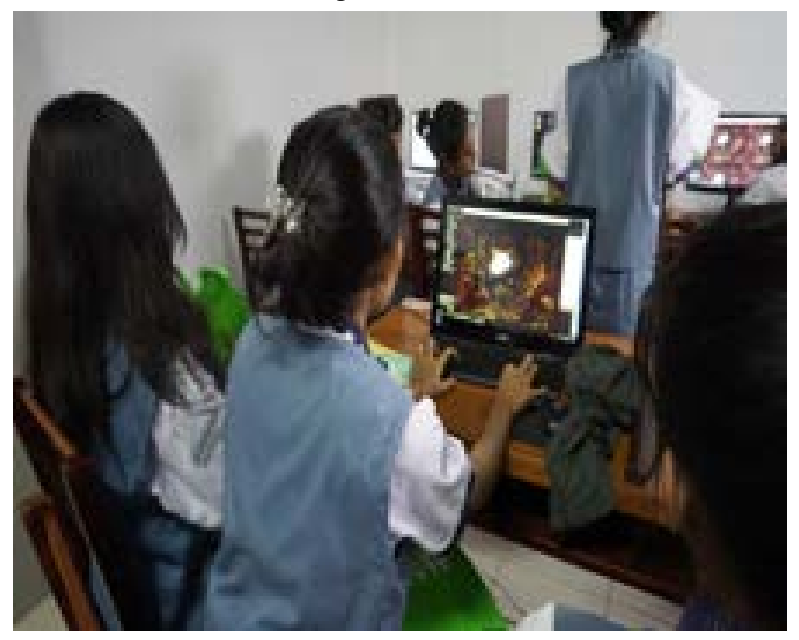

Gambar 5. Para peserta memperhatikan pelatihan

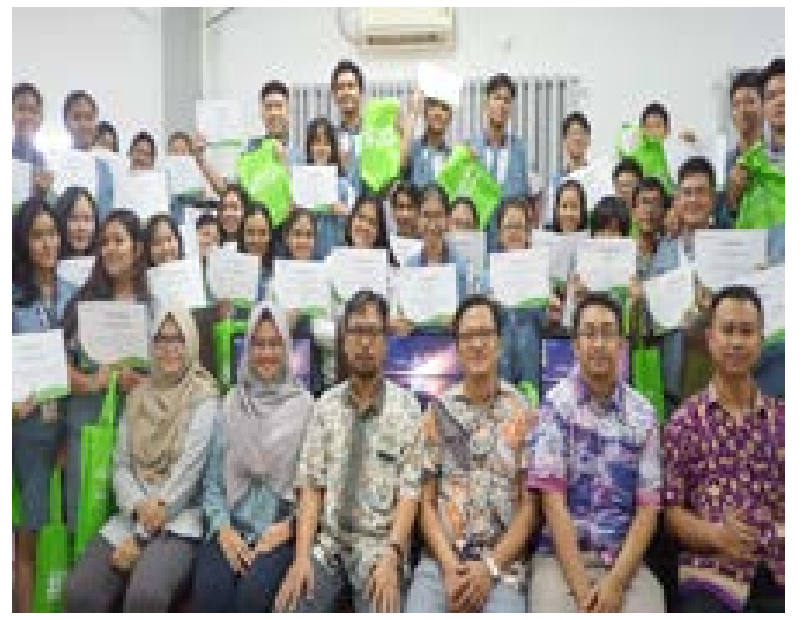

Gambar 6. TIM PKM bersama dengan para peserta

\section{SIMPULAN}

Kegiatan pelatihan yang telah dilaksanakan pada tanggal 08 April 2020 dapat disimpulkan bahwa kegiatan pelatihan ini memberikan pengetahuan mengenai konsep permainan dan aplikasi yang digunakan untuk membuat permainan. Para peserta terlihat sangat antusias mengikutinya materi pelatihan. Keingintahuan peserta sangat besar, hal ini menjadikan materi pelatihan dapat tersampaikan dengan baik. Materi pelatihan ini dapat dikembangkan sesuai dengan kreativitas para siswa-siswi dalam membuat permainan yang menarik.

Dengan memeperhatikan besarnya minat peserta mengikuti pelatihan ini, maka disarankan untuk dapat diberikan pelatihan lanjutan tentang aplikasi yang dapat mendukung dan meningkatkan kemampuan dan kompetensi di bidang teknologi informasi siswa/i guna menghadapi era industri 4.0.

\section{DAFTAR RUJUKAN}

Bisoglio, J., Michaels, T. I., Mervis, J. E., \& Ashinoff, B. K. (2014). Cognitive enhancement through action video game training: Great expectations require greater evidence. Frontiers in Psychology, 5(FEB), 1-6. https://doi.org/10.3389/fpsyg.2014.00136

Direktorat Jenderal Pendidikan Anak Usia Dini, P. D. dan P. M., \& Kebudayaan, K. P. dan. (2020). Data Pokok SMAS KRISTEN TERANG BANGSA - Dapodik.pdf. Kementerian Pendidikan dan Kebudayaan.

Direktorat Riset dan Pengabdian Masyarakat, Dirjen Penguatan Riset dan Pengembangan Kementerian Riset, Teknologi, dan P. T. (2018). Panduan Penelitian dan Pengabdian Kepada Masyarakat Edisi XII.

Dirgantara, H. B., Prabowo, Y. D., \& Jermia, M. M. (2019). Development of android-based quiz video game: Mathventure. Proceedings - International Joint Conference on Information, Media, and Engineering, IJCIME 2019, 450-454. https://doi.org/10.1109/ IJCIME49369.2019.00097

GamingScan. (2020). 2020 Gaming Industry Statistics, Trends \& Data. https://www.gamingscan.com/gamingstatistics/

Granic, I., Lobel, A., \& Engels, R. C. M. E. (2014). The benefits of playing video games. American Psychologist, 69(1), 66-78. https://doi.org/10.1037/a0034857

Institut Teknologi dan Bisnis Kalbis. (2019). Panduan Pengabdian Kepada Masyarakat, Institut Teknologi dan Bisnis Kalbis. 